\title{
Utilização do infiltrômetro de cornell e dos anéis concêntricos para determinação da infiltração de água em um Latossolo Vermelho
}

\author{
Soil water infiltration measurements using the double ring and \\ cornell infiltrometer in a Rhodic Hapludox
}

\author{
Anderson Luiz Zwirtes ${ }^{1 *}$; Renato Beppler Spohr ${ }^{2}$; Cléber Antonio Baronio ${ }^{3}$; \\ Diego Ricardo Menegol'; Genesio Mario da Rosa ${ }^{2}$; Moacir Tuzzin de Moraes ${ }^{5}$
}

\begin{abstract}
Resumo
A determinação da infiltração de água no solo é uma informação de extrema relevância em diversas áreas como, por exemplo, na agricultura, recursos hídricos, projetos de engenharia. Os métodos utilizados na determinação da infiltração de água em geral são trabalhosos a produzem muitas vezes, resultados pouco confiáveis. Este trabalho teve como objetivo avaliar o método do infiltrômetro de duplo anel e o infiltrômetro de Cornell para determinação da taxa de infiltração de água em um Latossolo Vermelho Aluminoférrico, submetido a três sistemas de manejo. Nos três sistemas de manejo, as taxas de infiltração determinadas pelo infiltrômetro de duplo anel apresentaram valores mais elevados quando comparado aos resultados obtidos com o infiltrômetro de Cornell. Para ambos os métodos, a área de mata nativa apresentou maior taxa de infiltração de água no solo, seguida pelas áreas manejadas com sistema plantio direto e pastagem perene cultivada. As taxas de infiltrações obtidas pelo infiltrômetro de anel foram de 1.428,2 $\mathrm{mm} \mathrm{h}^{-1}$ (mata nativa), $46 \mathrm{~mm} \mathrm{~h}^{-1}$ (plantio direto) e 22,6 $\mathrm{mm} \mathrm{h}^{-1}$ (pastagem perene). As mesmas áreas com o infiltrômetro de Cornell apresentaram taxas de infiltração de 300 , 33,2 e 12,7 $\mathrm{mm} \mathrm{h}^{-1}$, respectivamente. A área de mata nativa não apresentou escoamento superficial, já as áreas de sistema plantio direto e pastagem perene cultivada apresentaram, respectivamente, início do escoamento superficial aos 3,25 e 1,33 minutos após o início dos testes.
\end{abstract}

Palavras-chave: Escoamento superficial, plantio direto, mata nativa

\begin{abstract}
The value of soil water infiltration is very important in several areas, such as agriculture, water resources, engineering projects. The methods to determinate the water infiltration in general is difficult and produce often unreliable results. The work aimed to evaluate the soil water infiltration rate in a Rhodic Hapludox under three management systems. The results were compared using two methods to determine the water infiltration rate. In the three management systems, the water infiltration rate in the soil was determined using the double ring infiltrometer. Using this method the results showed higher values when compared to the Cornell infiltrometer. For both methods, the native forest presented the

\footnotetext{
${ }^{1}$ Eng $^{\mathrm{o}} \mathrm{Agr}^{\mathrm{o}}$, M.e Discente de Doutorado em Ciência do Solo, Universidade Federal de Santa Maria, UFSM, Santa Maria, RS. E-mail: andersonzwirtes@yahoo.com.br

${ }^{2}$ Eng $^{\circ \mathrm{s}} \mathrm{Agr}^{\circ \text { s }}$, Profs. Drs. do Dept ${ }^{\circ}$. de Engenharia Florestal, UFSM, campus Frederico Westphalen, RS. E-mail: renatospohr@ smail.ufsm.br; genesiomario@yahoo.com.br

${ }^{3}$ Eng $^{\circ}$ Agr $^{\circ}$, Discente de Mestrado em Fitossanidade, Universidade Federal de Pelotas, UFPEL, Pelotas, RS. E-mail: cleber. baronio@hotmail.com

${ }^{4}$ Eng $^{\mathrm{O}} \mathrm{Agr}^{\mathrm{o}}$, Discente de Mestrado em Agronomia, Agricultura e Ambiente, UFSM, Frederico Westphalen, RS. E-mail: menegoldr@ gmail.com

${ }^{5} \mathrm{Eng}^{\mathrm{o}} \mathrm{Agr}^{\circ}$, M.e Discente de Doutorado em Ciência do Solo, Universidade Federal do Rio Grande do Sul, UFRGS, Porto Alegre, RS. E-mail: moacir.tuzzin@gmail.com

* Autor para correspondência
}

Recebido para publicação 09/08/12 Aprovado em 17/05/13 
highest soil water infiltration rate, followed by the no tillage area and perennial pasture grown. Through the double ring infiltrometer the infiltration rates obtained were $1428.2 \mathrm{~mm} \mathrm{~h}^{-1}$ (Forest), $46 \mathrm{~mm} \mathrm{~h}^{-1}$ (no tillage) and $22.6 \mathrm{~mm} \mathrm{~h}^{-1}$ (perennial pasture). Considering the Cornell infiltration method, the same areas showed infiltration rates of $300,33.2$ and $12.7 \mathrm{~mm} \mathrm{~h}^{-1}$, respectively. In the native forest the runoff process was not verified, while ingress with no tillage and perennial pasture. In these areas the runoff is started, respectively, at 3.25 and 1.33 minutes after the beginning of the tests.

Key words: Runoff, no tillage, native forest

\section{Introdução}

O conhecimento da dinâmica da água no solo está diretamente relacionado com a produção vegetal, tornando-se fundamental para decisões sobre o uso e manejo dos solos (CALHEIROS et al., 2009). A taxa de infiltração de água no solo (TI) é um importante parâmetro para avaliar a qualidade física do solo, devido à integralização de características como estabilidade de agregados, selamento superficial, distribuição e tamanho de poros (REICHERT et al., 2009).

A infiltração de água no solo é o processo da passagem da água através da superfície do solo (BERNARDO; SOARES; MANTOVANI, 2006). Através da melhoria nas condições de infiltração de água no solo ocasiona uma redução nos processos erosivos e estimula a recarga dos aquíferos subterrâneos, além de reduzir as vazões máximas dos cursos d'água, sendo um componente determinante do balanço hídrico na região da zona radicular da cultura (CECÍLIO et al., 2007). Este processo é influenciado por grande número de fatores relativos ao solo e as condições a que ele é submetido (PRUSKI et al., 1997). Dependendo principalmente de fatores relacionados com a superfície, preparo e manejo do solo, considerando estes como fatores condicionantes dos meios porosos que se relaciona com o movimento da água no solo e encrostamento superficial (BRANDÃO et al., 2006).

O manejo do solo é apresentado como sendo grande responsável por alterações na TI. Neste sentido, o sistema plantio direto (SPD) é responsável pela elevação dos valores deste atributo quando comparados ao sistema de preparo convencional (ALVES; CABEDA, 1999; ALVES SOBRINHO et al., 2003). Ao contrário dos poros produzidos pela mobilização mecânica do solo, em SPD os bioporos são longos e contínuos e, assim, de alta efetividade para a transmissão de água e ar (OADES, 1993). Porém, podem ocorrer reduções desta taxa em decorrência do adensamento de partículas e do aumento do nível de compactação nas camadas superficiais do solo (PINHEIRO; TEIXEIRA; KAUFMANN, 2009).

A determinação da infiltração de água no solo pode ser realizada através de diferentes métodos, tais como infiltrômetro de duplo anel, simulador de chuva (PRUSKI et al., 1997, BERNARDO; SOARES; MANTOVANI, 2006; BRANDÃO et al., 2006), infiltrômetro de tensão, permeâmetro e/ ou infiltrômetro de pressão (POTT; DE MARIA, 2003). A seleção dos métodos de determinação da TI depende do sistema de irrigação a ser utilizado, por exemplo, para dimensionamento de sistemas de irrigação por aspersão é recomendado o uso de simuladores de chuva (BOWER, 1986). A utilização de métodos que não consideram o impacto das gotas de chuva pode ocasionar superestimação dos valores de infiltração de água no solo, gerando problemas no dimensionamento de projetos de irrigação e drenagem, subdimensionamento de projetos conservacionistas, resultando em problemas com a erosão do solo (POTT; DE MARIA, 2003). O infiltômetro de Cornell é um simulador de chuva portátil, fixado sobre um cilindro de $24 \mathrm{~cm}$ de diâmetro e conta com um sistema de regulagem de entrada de ar, o qual permite simular diferentes intensidades de chuva. Suas vantagens envolvem o baixo custo de aquisição, praticidade no transporte (tamanho pequeno e peso baixo), avaliação rápida e determinada por uma única pessoa, facilidade de 
calibração para diferentes intensidades de chuva e baixo consumo de água. O infiltrômetro de Cornell apresenta vantagens em relação ao método de duplo anel, devido à menor necessidade de mão de obra para operar o equipamento, além de redução do período de realização do teste e menor consumo de água (SANTI, 2007). Porém, são escassos os estudos da avaliação do desempenho do infiltrômetro de Cornell e dos anéis concêntricos na determinação da TI em Latossolos (SANTI et al., 2012), sendo necessário, comprovar o desempenho destes aparelhos submetidos à diferentes sistemas de manejos de um Latossolo Vermelho.

Este trabalho teve como objetivo avaliar o método do infiltrômetro de duplo anel e o infiltrômetro de Cornell para determinação da TI em um Latossolo Vermelho Aluminoférrico típico, submetido a três sistemas de manejo.

\section{Material e Métodos}

O trabalho foi desenvolvido na área experimental da Universidade Federal de Santa Maria, campus de Frederico Westphalen, RS, em um Latossolo Vermelho Aluminoférrico típico (SANTOS et al., 2013), com textura muito argilosa. Foi utilizado o delineamento experimental inteiramente casualizado, em esquema fatorial $2 \times 3$ (métodos de determinação da infiltração x sistemas de manejo do solo), com quatro repetições. Os métodos de determinação da TI utilizados foram: o infiltrômetro de duplo anel e o infiltrômetro de Cornell. Os sistemas de manejo avaliados foram Mata nativa (MN), Pastagem perene cultivada com tifton (cynodon sp) (PPC) e Sistema plantio direto (SPD) consolidado à nove anos.

O infiltrômetro de Cornell (Figura 1) consiste de um reservatório de aproximadamente 20,6 litros, contendo na parte inferior 69 microtúbulos de $0,063 \mathrm{~cm}$ de diâmetro por $19 \mathrm{~cm}$ de comprimento, esse conjunto é fixado sobre um cilindro com $24 \mathrm{~cm}$ de diâmetro e cravado no solo (VAN ES; SCHINDELBECK, 2003). Quando em operação, esse equipamento simula uma chuva de alta intensidade e o escoamento superficial de água no solo (ES) é determinado a partir da coleta do excesso de água em uma mangueira instalada na parte inferior do anel. Para a determinação do ES com este equipamento foi utilizado uma intensidade média de chuva em torno de $300 \mathrm{~mm} \mathrm{~h}^{-1}$. Apesar do infiltrômetro de Cornell permitir a aplicação de intensidades menores que $300 \mathrm{~mm} \mathrm{~h}^{-1}$, ao utilizálas foi observada uma dificuldade em manter a taxa de aplicação constante, isto causa uma variação indesejável nos valores de TI. O início do ES foi contabilizado a partir da formação de um filete contínuo de água na saída da mangueira coletora. A leitura do volume de ES foi realizada a cada $3 \mathrm{~min}$. A intensidade da chuva foi controlada através das diferenças de leituras, a cada $3 \mathrm{~min}$, do volume de água no reservatório. As leituras da intensidade da chuva e ES foram realizadas simultaneamente. A TI foi calculada pela diferença entre a chuva aplicada e o ES. Cada teste tinha duração de aproximadamente $60 \mathrm{~min}$, conforme a metodologia descrita por Van Es e Schindelbeck (2003).

O infiltrômetro de duplo anel consiste de um conjunto de dois anéis concêntricos, o primeiro com $20 \mathrm{~cm}$ e o segundo com $40 \mathrm{~cm}$ de diâmetro, ambos são introduzidos até uma profundidade de $15 \mathrm{~cm}$ da superfície do solo. O reservatório de água possui uma graduação em milímetros, onde é realizada a leitura e determinação da quantidade de água infiltrada no anel interno. Foi mantida uma lâmina de água média de 4 a $5 \mathrm{~cm}$ no anel interno e externo. $\mathrm{O}$ anel externo tem a finalidade de minimizar a dispersão lateral de água. As leituras foram realizadas até o tempo decorrido de $120 \mathrm{~min}$ do início do teste, conforme metodologia apresentada por Bernardo, Soares e Mantovani (2006). 
Figura 1. Vista esquemática de perfil do infiltrômetro de Cornell. H é a altura da carga medida durante os testes para controle da intensidade da chuva. Frederico Westphalen, RS, 2012.

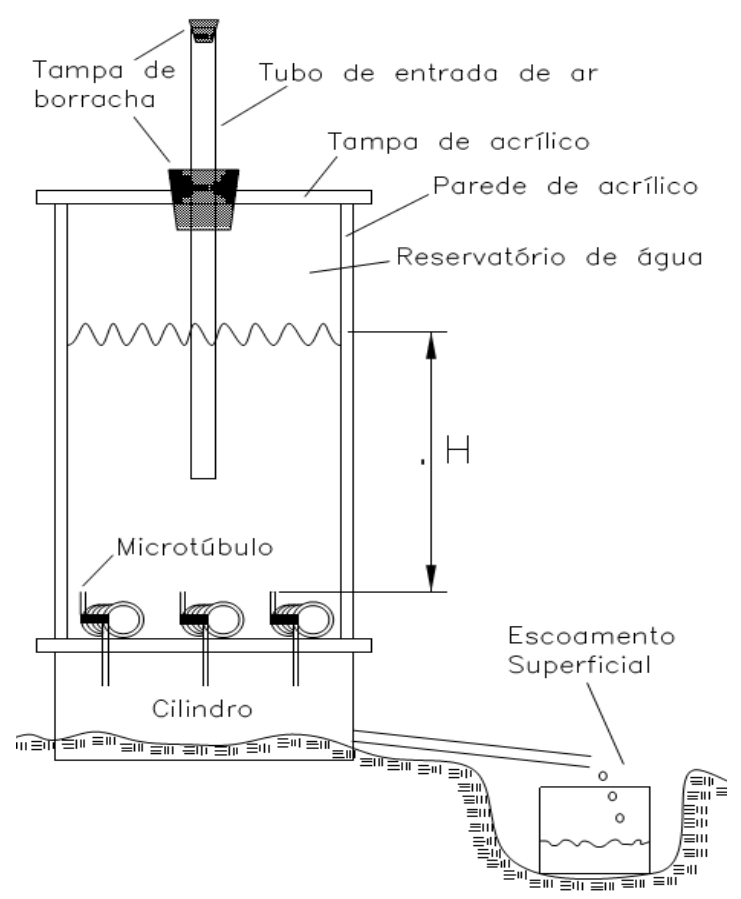

Fonte: Adaptado de Ogden, Van Es e Schindelbeck (1997).

Ambos os métodos (infiltrômetro de Cornell e infiltrômetro de duplo anel), a taxa de infiltração estável (TIE) do solo foi considerada como sendo o valor médio das três últimas leituras.Os resultados de ES, obtidos nos testes com o infiltrômetro de Cornell, foram ajustados por meio da equação 1, derivada do modelo matemático determinado por Smith, conforme descrita por Carlesso et al. (2011).

$$
e=e_{c}\left\{1-\left(\frac{t_{e}}{t}\right)^{b}\right\}, \text { para } t>t_{e}
$$

em que, $e$ é a taxa de escoamento superficial de água no solo (ES) em um tempo $\mathrm{t}\left(\mathrm{mm} \mathrm{h}^{-1}\right) ; e_{c}$ é a taxa de escoamento constante; $t_{e}$ é o tempo de início do ES (min); $t$ é o tempo após o início do ES (min) e $b$ é o parâmetro de ajuste do modelo.

O tempo de início do $\mathrm{ES}\left(\mathrm{t}_{\mathrm{e}}\right)$ foi obtido a campo, tomando como referência o momento em que iniciou a saída de água pela mangueira coletora do infiltrômetro.
O ajuste das curvas de infiltração obtidos através do infiltrômetro de duplo anel foi realizado utilizado o modelo matemático proposto por Kostiakov (Equação 2), apresentado por Bernardo, Soares e Mantovani (2006):

$$
I=K \cdot T^{u}
$$

Eq. 2

em que, $I$ é a infiltração acumulada ( $\mathrm{mm}), K$ é o parâmetro dependente da condição de umidade inicial do solo; $\mathrm{T}$ é tempo de oportunidade de infiltração (horas ou min); e $a$ é constante dependente do solo, variando entre 0 e 1 .

Amostras indeformadas de solo foram coletadas, nas camadas de 0,0-0,1 e 0,1-0,2 m, com anel volumétrico para a determinação da densidade do solo (EMBRAPA, 1997a), e do limite superior de água disponível às plantas. As amostras de solo foram coletadas aproximadamente $24 \mathrm{~h}$ após a ocorrência de uma chuva significativa (aproximadamente 80 $\mathrm{mm}$ ), a qual promoveu umedecimento completo do solo e drenagem do excesso de água. 
Os resultados das variáveis, densidade do solo e limite superior de água disponível, foram submetidas à análise de variância (Teste $\mathrm{F}, \mathrm{p}<0,05) \mathrm{e}$ as médias, quando significativas, foram comparadas pelo teste de Tukey, a $5 \%$ de probabilidade de erro. As análises estatísticas foram realizadas conforme indicado por Storck et al. (2002), utilizando-se o programa estatístico SOC-NTIA (EMBRAPA, 1997b).

\section{Resultados e Discussão}

$\mathrm{Na}$ Tabela 1 são apresentadas algumas características físicas do solo nos diferentes sistemas de manejo avaliados. Foi observado que a área com mata nativa apresentou maior declividade (15\%) em relação às demais áreas. A menor declividade foi obtida na área de PPC (6\%). Neste sentido, Dalla Santa (2010) destaca que maiores declividades do terreno resultam em menor tempo para o inicio do ES, maiores taxas de ES e consequentemente resultam em menores taxas de infiltração de água no solo.

Tabela 1. Declividade, densidade do solo e limite superior de água disponível em solo manejado sob sistema plantio direto, pastagem perene cultivada com tifton e mata nativa em um Latossolo Vermelho Aluminoférrico. Frederico Westphalen, RS, 2012.

\begin{tabular}{|c|c|c|c|c|c|}
\hline \multirow[t]{3}{*}{ Local } & \multirow{3}{*}{$\begin{array}{l}\text { Declividade } \\
\text { (\%) }\end{array}$} & \multicolumn{2}{|c|}{$\begin{array}{c}\text { Densidade do solo } \\
\qquad\left(\mathrm{Mg} \mathrm{m}^{-3}\right)\end{array}$} & \multicolumn{2}{|c|}{$\begin{array}{c}\text { Limite superior de } \\
\text { água disponível } \\
\left(\mathrm{m}^{3} \mathrm{~m}^{-3}\right)\end{array}$} \\
\hline & & \multicolumn{4}{|c|}{ Profundidade (m) } \\
\hline & & $0-0,1$ & $0,1-0,2$ & $0-0,1$ & $0,1-0,2$ \\
\hline Sistema plantio direto & $9 \%$ & $1,38 b^{*}$ & $1,28 \mathrm{~b}$ & $0,49 \mathrm{a}$ & $0,42 a b$ \\
\hline Pastagem perene cultivada & $6 \%$ & $1,51 \mathrm{c}$ & $1,46 \mathrm{c}$ & $0,42 \mathrm{ab}$ & $0,43 \mathrm{a}$ \\
\hline Mata nativa & $15 \%$ & $0,94 \mathrm{a}$ & $1,05 \mathrm{a}$ & $0,37 \mathrm{~b}$ & $0,38 \mathrm{~b}$ \\
\hline
\end{tabular}

*Médias seguidas de mesma letra na coluna não diferem entre si pelo teste de Tukey a 5\%.

Fonte: Elaboração dos autores.

A área de mata nativa apresentou menor densidade do solo, diferindo significativamente das demais áreas, para as camadas de 0,0-0,1 e 0,10,2 m. A área de PPC apresentou maior densidade do solo, para as duas camadas em relação aos demais tratamentos (mata nativa e SPD). Este comportamento é atribuído à ocupação da área para pastoreio do gado, causando a compactação do solo, corroborando com resultados de Lanzanova et al. (2007). A área sob SPD apresentou maior umidade volumétrica do solo, na camada de 0,0$0,1 \mathrm{~m}$, diferindo significativamente da área de mata nativa (Tabela 1). O incremento na retenção de água no solo, sob SPD em relação à mata nativa, está relacionada com a maior quantidade de microporos do solo, o que é atribuída à maior densidade do solo, pois a mata nativa apresenta menor densidade do solo e grande quantidade de material vegetal ainda em decomposição, favorecendo a presença de poros responsáveis pela redistribuição de água no solo. Reichardt e Tim (2004) descrevem o fator capilaridade como força atuante na retenção, redistribuição, consumo ou perda de água no solo, ocorre inicialmente nos poros maiores $(>50 \mu \mathrm{m})$. Neste sentido, quanto menor for o poro $(<50 \mu \mathrm{m})$, maior será a força com que a água estará retida no solo. Araujo, Tormena e Silva (2004), trabalhando em um Latossolo Vermelho Distrófico, observaram menor densidade do solo em área de mata, quando comparada a áreas cultivadas, atribuindo este comportamento ao baixo tráfego e maior quantidade de matéria orgânica na área de mata, apresentando influência da densidade do solo na retenção de água. 
A área de mata nativa não apresentou ES (Figura 2), indicando que a TI verificada foi semelhante à intensidade de chuva aplicada.

A área manejada sob SPD (Figura 2B) apresentou o início do ES após 3,25 min. Foi observado que, neste período inicial (3,25 $\mathrm{min}$ ), o solo apresentou TI igual ou superior a $300 \mathrm{~mm}$ $\mathrm{h}^{-1} \mathrm{e}$, em seguida, ocorreu uma rápida redução na TI, até 8,75 min após o início do ES. O início do ES na área de PPC (Figura 2C) ocorreu aos 1,33 min após o inicio dos testes, se estabilizando aos 12 min. Este comportamento é atribuído à elevada intensidade de chuva aplicada, causando uma rápida saturação do solo, consequentemente ocasionando o ES com posterior estabilização da TI. O aumento da intensidade da chuva provoca uma redução no tempo para que ocorra inicio do ES, ocasionando aumento das perdas, independente das condições da superfície do solo (CARLESSO et al., 2011). Santi (2007) utilizando o infiltrômetro de Cornell em um Latossolo Vermelho Distrófico típico, textura argilosa, observou início de escoamento entre 3 e 6 min, para intensidade de chuva próxima aos $300 \mathrm{~mm}$ $\mathrm{h}^{-1}$. Panachuki et al. (2006), utilizando simulador de chuva com intensidade de $100 \mathrm{~mm} \mathrm{~h}^{-1}$, observaram ES aos 1,16 min para área com pastagem continua e 3,87 min para área manejada com SPD.

Figura 2. Curvas ajustadas pelo modelo de Smith para o escoamento superficial e a taxa de infiltração de água no solo nas áreas de mata nativa (A), plantio direto (B) e pastagem perene cultivada com tifton (C) em um Latossolo Vermelho Aluminoférrico. Frederico Westphalen, RS, 2012.

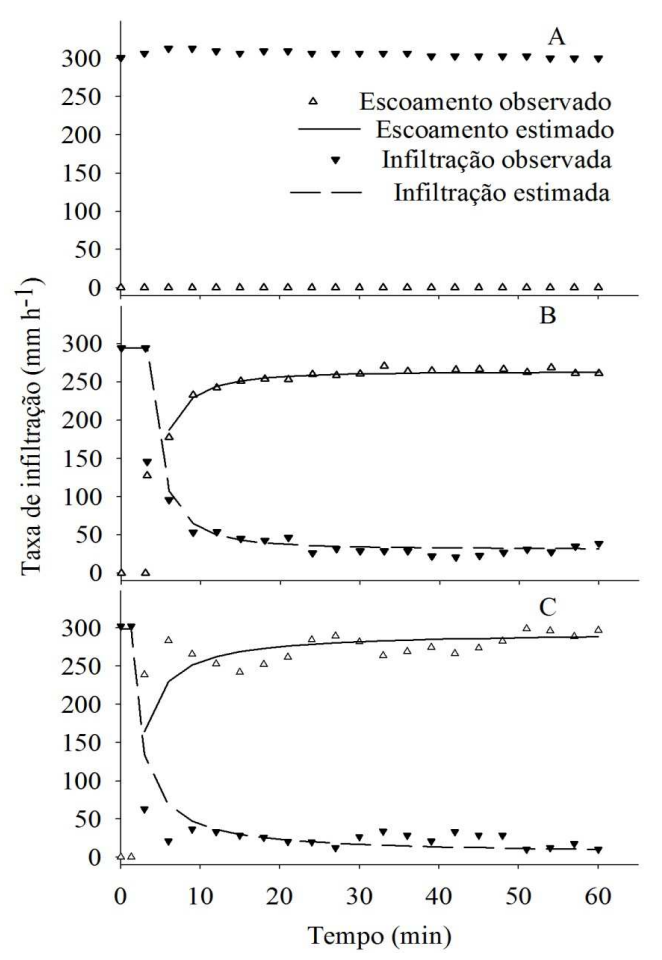

Fonte: Elaboração dos autores.

Os valores observados e estimados de ES (figura 2) não apresentaram elevada dispersão dos pontos em relação aos valores estimados pelo modelo de Smith, evidenciando um bom ajuste do modelo às condições do solo estudado. Spohr et al. (2009), encontraram para solos do Uruguai, satisfatório desempenho do modelo matemático de Smith para intensidade de chuva próximas a 100 e $60 \mathrm{~mm} \mathrm{~h}^{-1}$, 
e desempenho ruim para intensidades próximas a $30 \mathrm{~mm} \mathrm{~h}^{-1}$. Carlesso et al. (2011), observaram que em solos do Rio Grande do Sul, o modelo de Smith apresentou um desempenho bom para intensidade de chuvas em torno de $120 \mathrm{~mm} \mathrm{~h}^{-1}$, e satisfatório para intensidades em torno de 60 e $30 \mathrm{~mm} \mathrm{~h}^{-1}$.
A figura 3 apresenta as curvas de infiltração de água no solo determinadas a partir dos dados coletados com o infiltrômetro de duplo anel para as áreas de mata nativa, SPD e PPC.

Figura 3. Taxa de infiltração de água no solo obtidas com o infiltrômetro de duplo anel, para a área de mata nativa (A), sistema plantio direto (B), e pastagem perene cultivada com tifton (C) em um Latossolo Vermelho Aluminoférrico. Frederico Westphalen, RS, 2012.

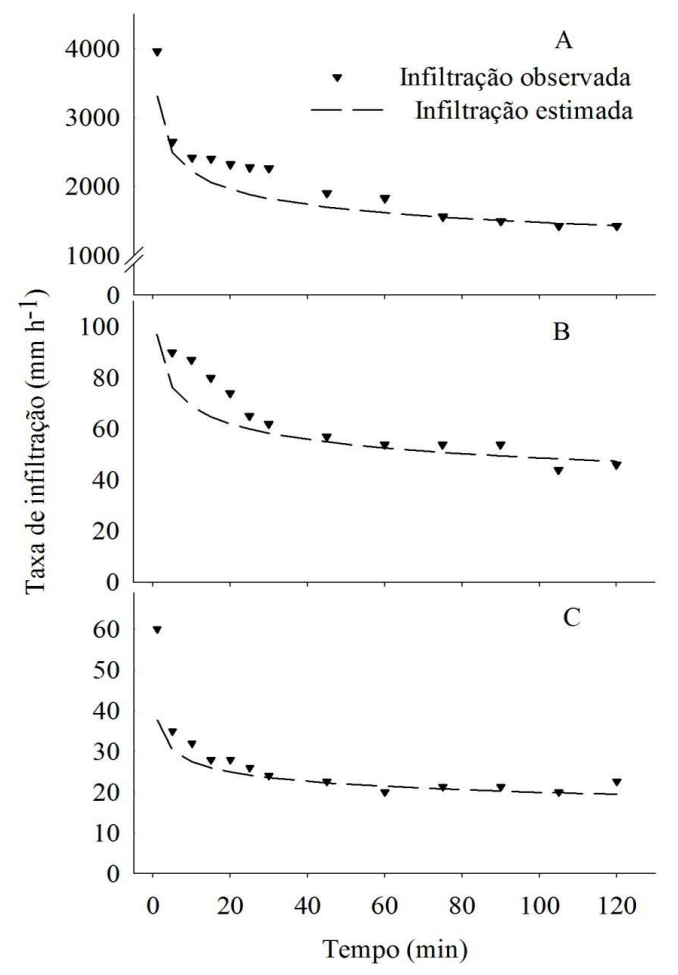

Fonte: Elaboração dos autores.

Foi observada elevada variação da TI entre as diferentes áreas de manejo avaliadas. A área de mata nativa apresentou TI com valores próximos de $1400 \mathrm{~mm} \mathrm{~h}^{-1}$ aos $120 \mathrm{~min}$. Os altos valores de TI na área de mata nativa estão relacionados à manutenção das características estruturais do solo como a alta porosidade, a baixa densidade do solo e a alta condutividade hidráulica. Além disso, a manutenção da serrapilheira na superfície do solo dificulta o ES e aumenta o tempo para que a água possa infiltrar no solo. A área de PPC apresentou uma elevada redução na TI quando comparada ao SPD (Figura 3). Estes resultados de variação da TI entre as áreas avaliadas são atribuídos às diferenças das características físicas das áreas (Tabela 1), principalmente em função da elevada densidade do solo no PPC, podendo ter ocasionado a redução da macroporosidade do solo, favorecendo a diminuições do fluxo de água e condutividade hidráulica do solo (STONE; GUIMARÃES; MOREIRA, 2002). Centurion, Cardoso e Natale (2001) encontraram comportamento semelhante, 
quando compararam as TI de áreas manejadas sob cultivos anuais com uma área de mata nativa.

As curvas de infiltração obtidas pelo infiltrômetro de duplo anel para a área de SPD e PPC (Figura 4) apresentaram TI superiores às verificadas para as mesmas áreas quando utilizado o infiltrômetro de Cornell. Santi et al. (2012) utilizaram os infiltrômetros de Cornell e duplo anel, e observaram valores semelhantes ao avaliar zonas de alta e baixa produtividade de grãos, sob SPD, manejado com agricultura de precisão. Resultados semelhantes aos deste estudo foram encontrados com a utilização de simuladores de chuva por Pruski et al. (1997) e Coelho, Miranda e Duarte (2000). Este efeito está relacionado com a formação de uma lâmina de água sobre a superfície do solo, quando é utilizado o duplo anel, a qual mantêm uma carga hidráulica constante, favorecendo a obtenção da taxa máxima de infiltração de água no solo (COSTA et al., 1999). Nos simuladores de chuva há o impacto das gotas d'água sobre a superfície do solo e também o ES favorecendo a desestruturação e o transporte de partículas, podendo ocasionar a formação de uma crosta superficial, a qual resultará em menores TI. No caso do infiltrômetro de Cornell, é pouco provável que o impacto da gota em solos protegidos com resíduo vegetal possa favorecer a formação do selamento, pois a altura da queda da gota d'água é muito pequena (aproximadamente $10 \mathrm{~cm}$ ). No entanto, assim como em simuladores de chuva, os efeitos causados pelo ES, como o transporte de partículas, podem ser observados nesse tipo de infiltrômetro.

Figura 4. Comparação da taxa de infiltração de água no solo estimada para a área manejada sob sistema plantio direto (A) e pastagem perene cultivada (B) em um Latossolo Vermelho Aluminoférrico. Frederico Westphalen, RS, 2012.

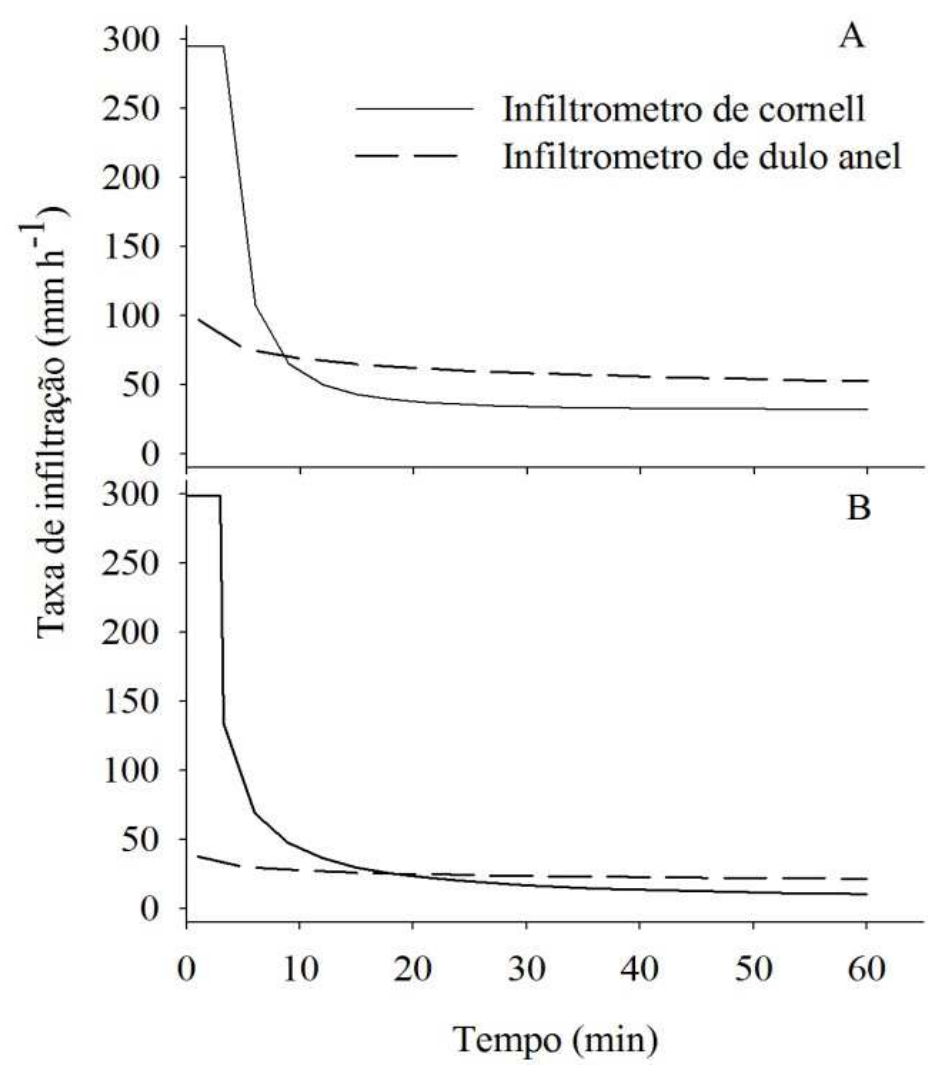

Fonte: Elaboração dos autores. 
Na tabela 2 foi apresentado a TIE para as diferentes áreas de manejo e métodos de determinação da infiltração de água no solo. Foi observado que, na área sob SPD, quando comparado os valores de TIE determinada com o infiltrômetro de Cornell em relação ao infiltrômetro de duplo anel, houve uma redução de $28 \%$ e $32 \%$ nos valores observados e estimados, respectivamente. Porém, quando foi observada a área ocupada com PPC, houve uma redução de 43 e $44 \%$ para os valores observados e estimados, respectivamente.

Tabela 2. Taxa de infiltração estável (TIE) de água no solo, observado e estimado em áreas sob diferentes sistemas de manejos do solo através dos dois métodos de determinação em um Latossolo Vermelho Aluminoférrico. Frederico Westphalen, RS, 2012.

\begin{tabular}{|c|c|c|c|c|}
\hline \multirow{3}{*}{ ÁREAS } & \multicolumn{2}{|c|}{ Observado } & \multicolumn{2}{|c|}{ Estimado* } \\
\hline & $\begin{array}{c}\text { Infiltrômetro } \\
\text { de Cornell }\end{array}$ & $\begin{array}{c}\text { Infiltrômetro duplo } \\
\text { anel }\end{array}$ & $\begin{array}{c}\text { Infiltrômetro de } \\
\text { Cornell }\end{array}$ & $\begin{array}{c}\text { Infiltrômetro } \\
\text { duplo anel }\end{array}$ \\
\hline & \multicolumn{4}{|c|}{ - ------------------------------------ $\mathrm{mm} \mathrm{h}^{-1}$----------------------------------- } \\
\hline Mata nativa & 300 & 1428 & - & 1432 \\
\hline Sistema plantio direto & 33 & 46 & 32 & 47 \\
\hline Pastagem perene cultivada & 13 & 23 & 11 & 19 \\
\hline
\end{tabular}

* Estimado a partir das equações ajustadas para um tempo de 120 minutos.

Fonte: Elaboração dos autores.

As TIE apresentaram diferenças conforme o manejo empregado em cada área. A área de SPD apresentou uma redução de 89 e $96 \%$ na TIE comparada à mata nativa (Tabela 2 ), respectivamente para as determinações com o infiltrômetro de Cornell e infiltrômetro de duplo anel. Comparando-se as TIE na área manejada com SPD e PPC, observase uma redução de 62 e 51\% nos valores obtidos através do infiltrômetro de Cornell e infiltrômetro de duplo anel, respectivamente. Alencar (2007) trabalhando em um Cambissolo Eutrófico de textura média verificou uma redução de $67 \%$ nas TIE ao realizar avaliação de infiltração anteriormente e posteriormente ao pastejo. Este autor atribuiu a diminuição na TIE após o pastejo ao possível encrostamento superficial do solo, em função do aumento da densidade do solo na camada superficial do solo $(0-5 \mathrm{~cm})$ ocasionado pelo pastejo da área. $\mathrm{O}$ pisoteio animal provoca um aumento da densidade e microporosidade do solo, ocasionando desta forma redução da macroporosidade, principalmente na camada superficial do solo (SALTON et al.,
2002). Mesmo estas camadas compactadas pelo pisoteio animal serem pouco espessas, seus efeitos sobre as propriedades físicas do solo influenciam acentuadamente as condições de infiltração de água (BRANDÃO et al., 2006), pois é através das camadas superficiais que a água deve passar, para infiltrar no solo. Neste sentido Panachuki et al. (2006), utilizando um simulador de chuva, observaram reduções na TIE em SPD quando comparado a solos manejados com pastagem de Brachiaria decumbens.

\section{Conclusões}

O infiltrômetro de duplo anel superestima os valores de infiltração de água no solo, quando comparados ao infiltrômetro de Cornell.

Os sistemas de manejos afetam as características físico-hídricas do solo.

Áreas, de Latossolo Vermelho Aluminoférrico típico, mantidas inalteradas com mata nativa apresentam menor densidade do solo e maior taxa de 
infiltração de água no solo, quando comparadas ao sistema plantio direto e pastagem perene cultivada.

Entre as áreas destinadas à produção agrícola, a área manejada com sistema plantio direto apresenta maior taxas de infiltração de água no solo, em relação à pastagem perene cultivada com tifton.

\section{Referências}

ALENCAR, C. A. B. Produção de seis gramineas forrageiras tropicais submetidas a diferentes lâminas de água e doses de nitrogênio, na região leste de minas gerais. 2007. Tese (Doutorado em Engenharia Agrícola) - Universidade Federal de Viçosa, Viçosa.

ALVES SOBRINHO, A. T.; VITORINO, A. C. T.; SOUZA, L. C. F.; GONÇALVES, M. C.; CARVALHO, D. F. Infiltração de água no solo em sistemas de plantio direto e convencional. Revista Brasileira de Engenharia Agricola e Ambiental, Campina Grande, v. 7, n. 2, p. 191196, 2003.

ALVES, M. C.; CABEDA, M. S. V. Infiltração de água em um Podzólico Vermelho escuro sob dois métodos de preparo, usando chuva simulada com duas intensidades. Revista Brasileira Ciências do Solo, Viçosa, v. 23, n. 1, p. 754-761,1999.

ARAujo, M. A.; TORMENA, C. A.; SILVA, A. P. Propriedades físicas de um Latossolo Vermelho distrófico cultivado e sob mata nativa. Revista Brasileira de Ciência do Solo, Viçosa, v. 28, n. 2, p. 337-345, 2004.

BERNARDO, S.; SOARES, A. A.; MANTOVANI, E. C. Manual de irrigação. 8. ed. Viçosa: UFV, 2006. 625 p.

BOWER, H. Intake rate: cylinder infiltrometer. In: KLUTE, A. (Ed.). Methods of soil analysis. Part 1 physical and mineralogical methods. 2. ed. Madison: SSSA, 1986. p. 825-844,

BRANDÃO, V. S.; CECILIO, R. A.; PRUSKI, F. F.; SILVA, D. D. Infiltração da água no solo. 3. ed. Viçosa: UFV, 2006. $120 \mathrm{p}$.

CALHEIROS, C. B. M.; TENÓRIO, F. J. C.; CUNHA, J. L. X. L.; SILVA, E. T.; SILVA, D. F.; SILVA, J. A. C. Definição da taxa de infiltração para dimensionamento de sistemas de irrigação por aspersão. Revista Brasileira Engenharia Agrícola e Ambiental, Campina Grande, v. 13, n. 6, p. 665-670, 2009.
CARLESSO, R.; SPOHR, R. B.; ELTZ, F. L. F.; FLORES, C. H. Runoff estimation in southern Brazil based on smith's modified model and the curve number method. Agricultural Water Management, Amsterdam, v. 98, n. 6, p. 1020-1026, 2011.

CECÍlIO, R. A.; MARTINEZ, M. A.; PRUSKI, F. F.; SILVA, D. D.; ATAIIDE, W. F. Substituição dos parâmetros do modelo de Green-Ampt-Mein-Larson para estimativa da infiltração em alguns solos do Brasil. Revista Brasileira de Ciência do Solo, Viçosa, v. 31, n. 5, p. 1141-1151, 2007.

CENTURION, J. F.; CARDOSO, J. P.; NATALE, W. Efeito de formas de manejo em algumas propriedades físicas e químicas de um Latossolo Vermelho em diferentes agroecossistemas. Revista Brasileira de Engenharia Agrícola e Ambiental, Campina Grande, v. 5, n. 2, p. 254-258, 2001.

COELHO, R. D.; MIRANDA, J. H.; DUARTE, S. N. Infiltração da água no solo: parte I infiltrômetro de anéis versus infiltrômetro de aspersão. Revista Brasileira de Engenharia Agrícola e Ambiental, Campina Grande, v. 4, n. 2, p. 137-141, 2000.

COSTA, E. L.; SILVA, A. M.; COLOMBO, A.; ABREU, A. R. Infiltração de água em solo, determinada por simulador de chuvas e pelo método dos anéis. Revista Brasileira de Engenharia Agrícola e Ambiental, Campina Grande, v. 3, n. 2, p. 131-134, 1999.

DALLA SANTA, C. Perdas de água por escoamento superficial de um solo com diferentes niveis de resíduos vegetais e declividades do terreno. 2010. Dissertação (Mestrado em Engenharia Agrícola) - Universidade Federal de Santa Maria, Santa Maria.

EMPRESA BRASILEIRA DE PESQUISA AGROPECUÁRIA - EMBRAPA. Ambiente de software NTIA, versão 4.2.2: manual do usuário - ferramental estatístico. Campinas: Centro Nacional de Pesquisa Tecnológica em Informática para a Agricultura, 1997b. $258 \mathrm{p}$.

Manual de métodos de análise de solo. 2. ed. Rio de Janeiro: Embrapa: Centro Nacional de Pesquisa de Solos, 1997a. 212 p.

LANZANOVA, M. E.; NICOLOSO, R. S.; LOVATO, T.; ELTZ, F. L. F.; AMADO, T. J. C. REINERT, D. J. Atributos físicos do solo em sistema de integração lavoura-pecuária sob plantio direto. Revista Brasileira de Ciência do Solo, Viçosa, v. 31, n. 5, p. 1131-1140, 2007. 
OADES, J. M. The role of biology in the formation, stabilization and degradation of soil structure. Geoderma, Amsterdan, v. 56, n. 1-4, p. 377-400, 1993.

OGDEN, C. B.; VAN ES, H. M.; SCHINDELBECK, R. R. Miniature rain simulator for field measurement of soil infiltration. Soil Science Society of America Journal, Madison, v. 61, n. 4, p. 1041-1043, 1997.

PANACHUKI, E.; ALVES SOBRINHO, T.; VITORINO, A. C. T.; CARVALHO, D. F.; URCHEI, M. A. Avaliação da infiltração de água no solo, em sistema de integração agricultura-pecuária, com uso de infiltrômetro de aspersão portátil. Acta Scientiarum. Agronomy, Maringá, v. 28, n. 1, p. 129-137, 2006.

PINHEIRO, A.; TEIXEIRA, L. P.; KAUFMANN, V. Capacidade de infiltração de água em solos sob diferentes usos e práticas de manejo agrícola. Revista Ambiente e Água, Taubaté, v. 4, n. 2, p. 188-199, 2009.

POTT, C. A.; DE MARIA, I. C. Comparação de métodos de campo para determinação da velocidade de infiltração básica. Revista Brasileira de Ciência do Solo, Viçosa, v. 27, n. 1, p. 19-27, 2003.

PRUSKI, F. F.; VENDRADE, V.; OLIVEIRA, E. F. de; BALBINO, L. C.; FERREIRA, P. A.; WERLANG, L.; CARVALHO, L. Infiltração da água num Latossolo Roxo. Pesquisa Agropecuária Brasileira, Brasília, v. 32, n. 1, p. 77-84, 1997.

REICHARDT, K.; TIMM, L. C. Solo, planta e atmosfera: conceitos, processos e aplicações. São Paulo: Manole, 2004. $478 \mathrm{p}$.

REICHERT, J. M.; SUZUKI, L.; REINERT, D. J.; HORN, R.; HAKANSSON, I. Reference bulk density and critical degree-of-compactness for no-till crop production in subtropical highly weathered soils. Soil and Tillage Research, Amsterdam, v. 102, n. 2, p. 242254, 2009.

SALTON, J. C.; FABRÍCIO, A. C.; MACHADO, L. A. Z.; OLIVEIRA, H. Pastoreio de aveia e compactação do solo. Revista Plantio Direto, Passo Fundo, v. 69, n. 1, p. 32-34, 2002.
SANTI, A. L. Relações entre indicadores de qualidade do solo e a produtividade das culturas em áreas com agricultura de precisão. 2007. Tese (Doutorado em Ciência do Solo) - Universidade Federal de Santa Maria, Santa Maria.

SANTI, A. L.; AMADO, T. J. C.; SILVA, V. R.; BASSO, C. J.; DELLA FLORA, L P.; CHERUBIN, M. R.; EITELWEIN, M. T. Infiltração de água no solo, determinada por diferentes métodos, como indicador do potencial produtivo em dois Latossolos manejados com agricultura de precisão. Interciencia, Caracas, v. 37, n. 3, p. 2004-2008, 2012.

SANTOS, H. G.; JACOMINE, P. K. T.; ANJOS, L. H. C.; OLIVEIRA, V. A.; LUBRERAS, J. F.; COELHO, M. R.; ALMEIDA, J. A.; CUNHA, T. J. F.; OLIVEIRA, J. B. (Ed.). Sistema brasileiro de classificação de solos. 3. ed. rev. ampl. Brasília: Embrapa, 2013. 353 p.

SPOHR, R. B.; CARLESSO, R.; GALLÁRRETA, C. G.; PRÉCHAC, F. G.; PETILLO, M. G. Modelagem do escoamento superficial a partir das características físicas de alguns solos do Uruguai, Ciência Rural, Santa Maria, v. 39, n. 1, p. $74-81,2009$.

STONE, L. F.; GUIMARÃES, C. M.; MOREIRA, J. A. A. Compactação do solo na cultura do feijoeiro. I: efeitos nas propriedades físico-hídricas do solo. Revista Brasileira de Engenharia Agrícola e Ambiental, Campina Grande, v. 6, n. 2, p. 207-212, 2002.

STORCK, L.; LÚCIO, A. D.; LOPES, S. J.; CARGNELUTTI FILHO, A. Procedimentos de análise $e$ interpretação de experimentos usando o pacote estatístico NTIA/Embrapa. Santa Maria: Departamento de Fitotecnia/UFSM, 2002. 145 p.

VAN ES, H.; SCHINDELBECK, R. Field procedures and data analysis for the cornell sprinkle infiltrometer. Ithaca, NY: Cornell University, Department of Crop and Soil Sciences Series R03-01, 2003. 8 p. 
